\section{Dêixis temporal e pessoal na construção da argumentatividade em artigos de opinião}

Temporal and personal deixis in construction of argumentativity in opinion articles
Julio Manoel da SILVA NETO (UFRJ) juliomassine@yahoo.com.br

Recebido em: 16 de out. de 2018. Aceito em: 14 de fev. de 2019.

in opinion articles


Abstract: In view of language argumentation theory (DUCROT, 1987; ANSCOMBRE; DUCROT, 1988; FIORIN, 2016; CABRAL, 2017) and referetiation process (KOCH; MARCUSCHI, 1998; MONDADA; DUBOIS, 2003; CIULLA; SILVA, 2008), this paper aims as deictics process (BENVENISTE, 1976; MAALEJ, 2003; CASTILHO, 2010; SANTOS; MORAIS, 2017) temporal and personal are important components in distinct opinion article, revealing argumentative goals of enunciators. Thus, evaluating the different lexical choices in speech, we verified that referetiation, through deixis, is a important means to reveal argumentative marks, transfused axiological positions.

Keywords: Referentiation. Argumentation. Deixis.

\section{Introdução}

O presente artigo almeja apresentar uma relação entre a referenciação e a argumentação. Para isso, selecionamos como objeto de análise artigos de opinião publicados sobre a temática Síria, entre 2015-2017. Dentre distintos elementos referenciais para observação, fixamos nosso olhar nas dêixis temporal e pessoal, pouco estudadas e que carecem de maior atenção em nossa área, a fim de apontarmos essa inter-relação presente entre dêixis e argumentação.

O artigo está dividido da seguinte maneira: na seção a seguir, apresentamos um breve panorama entre o conceito mais atual de

referenciação e também trazemos à tona seus principais processos referenciais. Na seção posterior, focamos nosso olhar na dêixis, indicando um breve estudo que aponta desde uma visão inicial sobre esse processo referencial, visto como fora do texto, até uma visão mais atual, que o abarca como um processo sociocognitivo discursivo, utilizado como elemento que auxilia na construção argumentativa. Após, apresentamos o nosso corpus, indicando como as dêixis de tempo e de pessoa auxiliam no caráter argumentativo dos artigos de opinião. Por fim, apresentamos nossas conclusões sobre o experimento apresentado.

Almejamos com este trabalho trazer à tona a importância desse elemento auxiliador na construção da argumentatividade, mas pouco discutido até então.

\section{Referenciação e processos referenciais}

Baseada na perspectiva da Linguística do Texto contemporânea, Koch (2014 [2008], p. 48) afirma ser a referenciação 
v. 9 (1)

270-286

jan-abr

2019

uma atividade discursiva. O sujeito, na interação, opera o material linguístico que tem à sua disposição, operando escolhas significativas para representar estados de coisas, com vistas à concretização do seu projeto de dizer (Koch, 1999, 2002). Isto é, os processos de referenciação são as escolhas do sujeito em função de um querer dizer [...] a realidade é construída, mantida e alterada não somente pela forma como nomeamos o mundo, mas acima de tudo pela forma como, sociocognitivamente, interagimos com ele: interpretamos e construímos nossos mundos por meio da interação com o entorno físico, social e cultural.

Assim, é possível compreendermos a referenciação como uma atividade discursiva na qual os objetos de discurso, uma vez inseridos no texto, (re)constroem-se e transformam-se de acordo com a maneira como interagimos com o mundo.

Exatamente por ser uma atividade discursiva, estudiosos sobre esse tema (KOCH; MARCUSCHI, 1998; MONDADA; DUBOIS, 2003) preferem usar o termo referenciação, e não referência. Em sua definição mais tradicional, referência é considerada como o ato de nomear, etiquetar os objetos do mundo, atribuindo-lhes uma relação de espelhamento do real. Já ao utilizarmos referenciação, ampliamos esse conceito, classificando-o como uma operação realizada para designar, representar ou sugerir algo dentro de uma situação sociodiscursiva. Isso não quer dizer, como salientam Koch e Marcuschi (1998, s/p), que "tudo se transforma numa panaceia subjetivista, mas que a discretização do mundo pela linguagem é um fenômeno discursivo". Nessa concepção de referenciação, as entidades designadas deixam de ser objetos do mundo, espelhos do real, e passam a objetos de discurso, virtuais, disponíveis para utilização pelo produtor do texto, atualizados no contexto interacional e dependentes de conhecimentos prévios que vão sendo atualizados ao longo do processo sociocognitivo.

Sintetizando esta ideia, temos o postulado por Mondada e Dubois (2003, p. 20):

[...] passando da referência à referenciação, vamos questionar os processos de discretização e de estabilização. Esta abordagem implica uma visão dinâmica que leva em conta não somente o sujeito "encarnado", mas ainda um sujeito sócio-cognitivo mediante uma relação indireta entre os discursos e o mundo.

No que tange aos objetos de discurso, esses são elementos aos quais fazemos retomadas nos textos, são estruturas, alimentadas pela atividade linguística, que se reformulam constantemente por 
meio de variados processos cognitivos. Segundo Cavalcante (2012, p. 98), podemos considerá-los como "uma entidade, uma representação construída a partir do texto e percebida, na maioria das vezes, a partir do uso de expressões referenciais", que se constituem por meio de repetição do mesmo termo, pronomes, elipses, sinônimos, hiperônimos, expressões que indicam avaliação do autor etc.

Cumpre salientar que os objetos construídos ao longo de um texto podem apresentar diferentes características estruturais, sendo mais ou menos individualizados, opacos, salientes, concretos, abstratos etc. Logo, é perceptível que há múltiplas maneiras de referenciar e (re)conhecê-las é extremamente importante para compreender como ocorre a composição dos textos.

A construção da referenciação realiza-se por estratégias de introdução (construção), retomada (manutenção) e desfocalização (KOCH; MARCUSCHI, 1998). A introdução é a inserção no cotexto de um "objeto" que até o momento ainda não havia sido mencionado e que, após sua inserção, passa a ficar em foco. A retomada é a reativação desse "objeto" já presente no texto por meio de uma forma referencial. A desfocalização, por fim, é a introdução de um novo "objeto", levando-o a ocupar a posição de maior relevância. O "objeto" anterior, contudo, não fica excluído, continua disponível para o produtor, podendo ser reativado a qualquer instante, caso seja necessário.

A repetição contínua dessas estratégias, ao mesmo tempo em que estabiliza o modelo textual, faz com que ele seja frequentemente modificado. Com isso, o processo de compreensão se torna extremamente complexo devido ao acréscimo contínuo de novas informações sobre o referente que foi inserido na introdução $(\mathrm{KOCH}, 2003)$. É necessário ressaltar, entretanto, que o fenômeno da referenciação não se restringe à remissão ou à retomada de elementos. Variados processos cognitivos estão inseridos nesse contexto, que conta também com aceitabilidade do interlocutor: "assim como o sentido, o referente advém do efeito de interação entre enunciadores e coenunciadores em atividades sociais conjuntas" (CAVALCANTE et al., 2010, p. 234).

Além de ser uma atividade discursiva, o processo referencial é capaz de estabelecer cadeias discursivas, indicando um querer-dizer do produtor do texto que pode se efetivar a partir da interação autortexto-leitor (cf. KOCH, 2003; SANTOS; CAVALCANTE, 2014), visto que o leitor precisa compreender essas estruturas construídas nas cadeias referenciais para possivelmente perceber as intencionalidades. 
V. 9 (1)

$270-286$

jan-abr

2019

Existem diferentes processos referenciais que nos auxiliam na (re)construção e (re)organização dos objetos do discurso. Estudar esses processos, segundo Machado (2016, p. 89) contribui

para um melhor entendimento do funcionamento das estruturas da língua, possibilitando ao leitor melhor compreensão dos textos e de seu lugar de coautor, além de garantir ao escritor ferramentas para expressar-se com mais precisão para obter sucesso no seu projeto de dizer.

Para Cavalcante et al. (2017, p. 96-97), são três os processos referenciais:

a. o de introdução referencial, porque há um momento em que os objetos de discurso são apresentados no texto pela primeira vez.

b. o de anáfora (ou retomada de referentes), porque, depois que os referentes são introduzidos, eles continuam no texto, girando em torno de temas e subtemas, fazendo-os progredir. c. o de dêixis (tipos de introdução ou de anáforas que só podem ser entendidas se as relacionarmos ao locutor e ao espaço ou tempo em que ele se encontra).

Restringiremos nossa análise ao item (c) dêixis.

\section{Tecendo relações entre argumentação e dêixis}

Os textos podem apresentar objetivos variados (enumerar elementos, darconselhos, pedirinformações, questionarposicionamentos etc.), contudo sua base estará sempre permeada pela argumentação linguística. Essa posição é assumida por autores variados como Ducrot (1987), Anscombre e Ducrot (1988), Fiorin (2016) e Cabral (2017).

Nas palavras de Anscombre e Ducrot (1988, apud FIORIN, 2016, p. 16), tratando da argumentação,

a utilização de um enunciado tem uma finalidade ao menos tão essencial quanto a de informar sobre a realização de suas condições de verdade, que é a de orientar o destinatário para certas conclusões e não para outras.

Para os autores, a argumentação acontece quando o locutor apresenta um enunciado (ou conjunto de enunciados) que leva a se admitir um outro. Se, naturalmente, todos os enunciados sempre encaminham para determinada conclusão que obtenha sentido, conclui-se que a argumentação é, assim, inerente não ao discurso, mas à língua, que, por sua vez, como sistema e instrumento do discurso, realiza-se na interatividade. 
Nesta perspectiva interativa, a língua é vista como um instrumento dialógico, na qual os interactantes se relacionam e buscam formas de convencer seu interlocutor, por isso Cabral (2017, p. 241) afirma que "o uso persuasivo da argumentação linguística implica escolhas e tomadas de decisões por parte do produtor em função de um querer dizer". Além disso, sendo a língua um instrumento dialógico, sempre responde a outros discursos - seja para aceitá-los, negá-los ou, até mesmo, ironizá-los, por exemplo - por essa razão, para Fiorin (2016, p. 29)

todos os discursos são argumentativos, pois todos eles fazem parte de uma controvérsia, refutando, apoiando, contestando, sustentando, contradizendo um dado posicionamento. Todos os discursos são argumentativos pois são uma ação responsiva a outro discurso.

Acreditando que a construção da argumentação é um elemento subjacente à língua (DUCROT, 1987), temos, assim, a formulação da Teoria da Argumentação na Língua, que se interessa "pelas possibilidades que a língua oferece para o uso e os limites que ela impõe" (CABRAL, 2017, p. 242).

Dentre múltiplos recursos que auxiliam na construção dos textos argumentativos, tais como os operadores argumentativos, por exemplo, salientamos o processo da dêixis.

Em revisão teórica, Mateu (1990) indica quea dêixiséa referência feita a objetos que não são conhecidos ou não estão introduzidos no discurso, ao passo que a anáfora faz referência a objetos que estão no discurso ou são geralmente conhecidos. Desse modo, tradicionalmente, teríamos a dêixis como processos coesivos que ocorrem "fora do texto", enquanto as anáforas como processos decorrentes "dentro do texto".

Por sua vez, para Fillmore (1997 [1984]), a interpretação dos processos dêiticos atrela-se diretamente ao momento da enunciação, aspecto também ratificado por Pires e Werner (2006), que afirmam que a dêixis se constrói por um "eu" na tentativa de se comunicar com os outros, por isso é considerada como uma categoria da enunciação e reveladora de subjetividades.

Perdicouyanni-Paléologou (2001, p. 60, tradução nossa) expõe que a dêixis exerce influência sobre três domínios (espaço, tempo e participantes): "isso nos permite falar de dêixis espacial, dêixis temporal e dêixis pessoal"1".

\footnotetext{
1 "cela nous permet de parler de dêixis spatiale, de déxis temporelle et de dêixis personnelle"
} 
v. 9 (1)

$270-286$

jan-abr

2019

Discorrendo sobre o tema, Castilho (2010, p. 123, grifos do autor) apresenta a frase "seguinte, neguinho, agora sou eu aqui e você lá, tá bom?", sobre a qual afirma que:

[...] ocorreram as seguintes expressões dêiticas: (i) eu indica o falante e aqui, o lugar que ele ocupa; (ii) você indica o interlocutor e o lá, o lugar que ele ocupa; (iii) agora indica um ponto na perspectiva temporal do discurso, implicando que desse ponto em diante a relação entre o interlocutores vai mudar.

Sendo assim, na frase de Castilho (2010), teríamos "eu" e "você" relativos à dêixis de pessoa, "aqui" e "lá" à dêixis de espaço e "agora" à dêixis de tempo.

A respeito desses três tipos de dêixis, com base em Benveniste (1976), podemos afirmar que a dêixis de pessoa institui, na interação, as marcas subjetivas de um sujeito enunciador - "eu" - e de seu(s) interlocutores - "tu", "você(s)". Essas marcas - "eu", "tu"/vocês(s)" - são construídas na e referem-se a realidades discursivas. Sendo assim, variando os discursos não serão os mesmos interlocutores a tomarem os mesmos postos enunciativos. Conforme aponta Benveniste (1976, p. 288, grifo do autor):

[o] eu se refere ao ato de discurso individual no qual é pronunciado, e lhe designa o locutor. É um termo que não pode ser identificado a não ser dentro do que, noutro passo, chamamos uma instância de discurso, e que só tem referência atual. A realidade à qual ele remete é a realidade do discurso.

A dêixis espacial e a temporal relacionam-se diretamente à pessoal, uma vez que marcam relações de aproximação/distanciamento (espaço) e momento (tempo) do enunciador no instante da enunciação. Como indica Fiorin (2001, p. 42, grifos do autor),

[...] todo espaço e todo tempo organizam-se em torno do "sujeito", tomado como ponto de referência. Assim, espaço e tempo estão na dependência do eu, que neles se enuncia. $\mathrm{O}$ aqui é o espaço do eu e o presente é o tempo em que coincidem o momento do evento descrito e o ato de enunciação que o descreve.

Para Filmore (1997 [1984]), há a ainda a dêixis social, que se traduz nas relações sociais estabelecidas na conversação, explorando expressões que podem indicar graus diferentes de formalidades, como "tu" e "vous" no francês, o primeiro indicando maior proximidade 
afetiva, relação entre os interlocutores, do que o segundo, tal como podemos associar com o "você" e "senhor(a)". Porém, concordamos com Fonseca (1992) e Santos e Cavalcante (2014) que defendem ser essa um subtipo da dêixis de pessoa, e não uma dêixis à parte, visto que o uso de tais formas relaciona-se apenas aos propósitos comunicativos que emergem de determinada situação enunciativa, que podem exigir, por exemplo, maior ou menor formalidade entre os interactantes.

Segundo Apothéloz (2003), há ainda mais dois tipos de dêixis: a de memória e a textual, que não abordaremos nesse artigo.

Como temos visto até então, a construção da dêixis parte sempre de uma referência dada pelo enunciador: o eu-aqui-agora. Avaliemos, contudo, o exemplo (1):

(1) Assad é um assassino, um carniceiro, um tirano. Não duvido de que possa ordenar um ataque químico. Ou ser conivente com ele. Ou optar pelo uso de armas químicas. Nunca duvide de nada ali. (V2)

Tradicionalmente, a expressão grifada, "ali", poderia ser classificada como um dêitico espacial, referindo-se a algum objeto no espaço distante do enunciador. Entretanto, se seguirmos uma perspectiva textual-discursiva, "ali" apenas pode ser classificado como uma anáfora direta recategorizadora com valor axiológico pejorativo, relacionando-se ao objeto do discurso (Bashar al) "Assad". A esse exemplo, somemos outros retirados de Santos e Cavalcante (2014), relativos ao uso dêitico de espaço:

Nossa acredita, até hoje eu não consigo mais ficar aqui no orkut, fiquei muito mal mesmo por terem excluído meu perfil... eu tinha muitas coisas escritas [...] (Disponível em:

<http://www.orkut.com.br/Main\#Home>. Acesso em 18/11/2013, apud SANTOS; CAVALCANTE, 2014, p. 231, grifos das autoras)

Segundo o apresentado pelas autoras, as expressões "hoje" e "eu" estariam relacionadas ao sujeito enunciador, funcionando, respectivamente, como dêixis temporal e pessoal. Contudo, "aqui" dependeria menos do enunciador para uma possível interpretação, visto que seu uso se associa mais à expressão "no orkut".

Já Maalej (2003), estudando os pronomes eu/nós/vocês nos discursos de Osni Mubarak, ex-presidente do Egito, e Cabral e Santos (2016), analisando, dentre outros elementos, o uso de eu/nós, na carta testamento de Getúlio Vargas, chegam a conclusões semelhantes: as 
v. 9 (1)

270-286

jan-abr

2019 escolhas dos pronomes expressam efeitos ideológicos, reconstruindo o outro a partir da perspectiva do "eu" enunciador. Observamos, dessa forma, que a dêixis não se restringe a situar as pessoas no espaçotempo, pois pode apresentar papel persuasivo, contribuindo para efeitos argumentativos.

Com base no elencado acima, definimos dêixis como "um processo que requer o conhecimento de algumas coordenadas relacionadas ao contexto espaço-temporal, aos interlocutores e também aos conhecimentos compartilhados sociocognitivamente" (SANTOS; MORAIS, 2017, p. 52).

Desse modo, acreditamos tanto que a dêixis é um processo de crucial importância para a construção do texto argumentativo quanto que a anáfora e a dêixis, em uma visão discursiva, precisam ser avaliadas em um continuum. Ciulla e Silva (2008, p. 60) ratifica esse último posicionamento ao afirmar que "a questão é que a dêixis e a anáfora parecem trilhar caminhos que não se interrompem, mas, pelo contrário, muitas vezes podem confluir".

Assim, além de uma determinada estrutura prototípica, abordagens discursivas devem ser privilegiadas como meio para se analisar dêixis ou anáfora, visto que esses não são processos excludentes, mas formas discursivas que se complementam, permitindo o processamento do texto pelos interlocutores (CABRAL; SANTOS, 2016).

\section{Construções dêiticas e escolhas argumentativas}

\section{Considerações iniciais}

Antes de nossa análise, é necessário evidenciar que tivemos poucos casos (mas significativos) de dêixis temporal e pessoal, além de também termos um corpus limitado, formado por artigos de opinião publicados entre 2015-2017 de três revistas, Veja, Época, Carta Capital, e um jornal, O Estado de São Paulo. A legenda para cada artigo apresentamos no quadro a seguir: 
Quadro 1: Corpus de artigos analisados

\begin{tabular}{|c|l|c|}
\hline $\begin{array}{c}\text { Meio de } \\
\text { comunicação }\end{array}$ & \multicolumn{1}{|c|}{ Título do artigo } & Código \\
\hline \multirow{2}{*}{ Veja } & "O pequeno jogo de Obama na Síria" & V1 \\
\cline { 2 - 3 } & $\begin{array}{c}\text { "Síria 2: Trump só está repetindo o erro de seu } \\
\text { antípoda: Obama!" }\end{array}$ & V2 \\
\hline \multirow{2}{*}{ Época } & "Teremos um novo 11 de setembro?" & E1 \\
\cline { 2 - 3 } & & C1 \\
\hline \multirow{2}{*}{ Carta Capital } & "Todos contra o Estado Islâmico" & C2 \\
\cline { 2 - 3 } & "Guerra na Síria: Só a piedade é pouco. É preciso ação" & O1 \\
\hline \multirow{2}{*}{$\begin{array}{c}\text { O Estado de } \\
\text { São Paulo }\end{array}$} & "A fanática visão única" & O2 \\
\cline { 2 - 3 } & "Qual a lógica de Assad ter usado armas químicas?" & \\
\hline
\end{tabular}

Fonte: autoria própria.

Cumpre ainda salientar que o gênero artigo de opinião, usado como corpus nesse artigo, por abordar temas atuais, é considerado um texto datado, ou seja, em um determinado tempo a temática apresentada pode não mais fazer sentido para o leitor. Além disso, como é próprio também desse gênero avaliar uma determina situação, expondo um posicionamento crítico, apoia-se bastante em datas variadas, objetivando situar o seu interlocutor num eixo temporal. Outra característica desse gênero é a sua marca pessoal, visto que o enunciador pode se inserir no discurso revelando um "eu" explícito em um diálogo com um "tu", almejando convencê-lo. Por isso, restringimos nossa análise às dêixis de tempo e pessoa.

\section{Análises do corpus}

Iniciemos com os exemplos de dêixis temporal em (02):

(02) Em quatro anos de guerra civil síria, o açougueiro Bashar Assad fez o que pôde para trucidar a oposição moderada, facilitando a vida dos jihadistas ensandecidos, a destacar o Estado Islâmico. [...]

[...] Experiente repórter que cobre o Oriente Médio, Ruth Sherlock diz que há três anos ela tinha as portas abertas dos círculos de poder em Washington quando queria conversar sobre as complexidades da crise síria. (V1)

As construções examinadas em (02) retomam a datas específicas da construção temporal do texto. Ou seja, só é possível contar as expressões temporais "em quatro anos" e "há três anos", tendo como base a data em que o artigo foi publicado, 30 de setembro de 2015. Esse aspecto da construção dêitica diferencia-se do que vemos nos exemplos (03) e (04) a seguir: 
v. 9 (1)

270-286

jan-abr 2019

(03) [...] Seu modelo é o islã antigo e uma adaptação radical da sharia, a lei religiosa islâmica. Ao longo dos séculos, os salafistas evitaram se envolver em política. Nos últimos anos, patrocinados por países do Golfo, ingressaram na política e aderiram à luta armada. [...]

Nos últimos meses, o EI mostrou que, mesmo quando atua no exterior, sua estratégia não é aterrorizar, mas conquistar. (E2)

(04) Vladimir Putin pedia há meses uma aliança comparável à de Stálin, Franklin D. Roosevelt e Winston Churchill, mas foi preciso os jihadistas imitarem Adolf Hitler e provocarem uma guerra em duas frentes, que igualmente pode vir a se mostrar um excesso fatal de autoconfiança de sua parte. (O1)

Todas as expressões grifadas - "nos últimos anos", "nos últimos meses", "há meses" - não revelam um momento específico, claro, como vimos no excerto (02). Dessa forma, não é possível mensurar qual é a quantidade de tempo que enunciador indicou, mesmo tendo como base $\mathrm{o}$ marco temporal das datas de produção dos textos, respectivamente, 02 de janeiro de 2015 e 19 de novembro de 2015. Assim, podemos considerar os casos mostrados em (03) e (04) como marcas suspensas no tempo, o que, na perspectiva argumentativa do artigo de opinião, pode corresponder a uma "estratégia do vago" (BARBOSA, 2014). A "estratégia do vago", baseada na "stratégie du flou" de Charaudeau, é apresentada por Barbosa (2014, p. 226) como uma

estratégia argumentativa que implica apresentar asserções gerais sobre determinado assunto, deixá-lo vago, a fim de evitar que algumas declarações mais incisivas e categóricas, e sobre as quais não se tem plena convicção da veracidade, sejam contraditas no futuro.

O autor aponta essa estratégia em uma perspectiva do discurso político. Entretanto, também podemos empregá-la no discurso jornalístico, em textos de opinião. Uma vez que o enunciador almeja a persuasão do seu auditório, vale-se da "estratégia do vago" evitando quaisquer possíveis futuros argumentos que invalidem seu pensamento argumentativo.

Outro exemplo que merece destaque no nosso corpus, pela frequência com que aparece, é "hoje", tradicionalmente visto como um dêitico temporal que marca um intervalo de dia, ou seja, 24 horas, tendo como pressuposto as marcas de enunciação do sujeito, quando produziu o discurso. Como indica Morais (2017, p. 127), analisando uma partida de futebol, "'hoje' implica uma noção de tempo que depende, para ser interpretada, do conhecimento do momento da enunciação". Notemos, entretanto, o exemplo (05): 
(05) Pode-se alegar que essa "teologia do terror" nasceu no cristianismo, com a Inquisição e as cruzadas. Mas a Igreja Católica renegou as fogueiras medievais e as apresentou como um criminoso desvio da fé cristã. Hoje, no século 21, sem fogueiras, espadas degolam ou fuzis e homens-bomba matam a esmo. (O1)

Em (05), "hoje" não se refere a um dia, mas a todo a um século. A esse exemplo, contrastemos com outros presentes em (06), (07) e (08):

(06) [...] Nosso homem em Moscou hoje cobra do mundo o posicionamento entre Assad e o terror; derrota para Barack Obama. O homem das nuances amarga um fiasco estratégico e humanitário na Síria. [...]

No entanto, no relato de Ruth Sherlock, a narrativa nos EUA (dos políticos e da mídia) é sobre a ameaça do Estado Islâmico. Experiente repórter que cobre o Oriente Médio, Ruth Sherlock diz que há três anos ela tinha as portas abertas dos círculos de poder em Washington quando queria conversar sobre as complexidades da crise síria. Hoje o único papo que interessa é esta ameaça do Estado Islâmico. (V1)

(07) A conquista histórica que hoje se materializa nisso a que damos o nome de opinião pública teve seu princípio nos cafés e nos saraus literários. Sem uma boa mesa de bar, não haveria o regime de liberdade. Simples assim. (E1)

(08) Complacentes, as grandes potências ocidentais os viram como alternativa para derrubar as ditaduras da Líbia e da Síria e, até, lhes deram armas. Hoje a vasta seita impermeável e rude invoca preceitos do Islã e, em nome de Alá, mata, escraviza, destrói populações inteiras e dinamita monumentos da História. [...]

Na Inquisição, o terror não foi obra dos fiéis católicos nem da doutrina cristã, mas da burocracia eclesiástica. Hoje, não é o povo muçulmano que mata nem é o Islã que comete os atentados. Mas sem a rigidez ideológica do Islã não existiriam atentados nem terror em nome de Alá. (01)

Nos excertos, o dêitico temporal "hoje" esvazia-se da marca temporal de 24 horas e também não indicia marca temporal fixa. "Hoje", em (06), (07) e (08), passa a indicar um intervalo maior de tempo em que uma determinada ação vigora, ao qual, por sua vez, nem nós nem o enunciador temos acesso de quando vai mudar. Esse aspecto é relevante, pois, novamente, notamos como os usos linguísticos não se restringem às suas características dadas a priori, mas atualizam-se no discurso, ganhando novos sentidos, corroborando, assim, para a observância de que a argumentação é um elemento subjacente à língua (DUCROT, 1987) e que múltiplos recursos podem ser usados para tal fim.

Abordamos, a seguir, as construções dêiticas de pessoa. Por ser próprio do gênero, o enunciador pode se manifestar em primeira pessoa, posicionando-se como em uma conversa com seu interlocutor. Como vemos em (09), (10) e (11): 
V. 9 (1)

270-286

jan-abr

2019
(09) E se foi Assad mesmo? Acompanho há anos o líder sírio e apenas uma vez vi uma ação que não teve lógica e talvez haja ligação com o seu regime. (O2)

(10) Escrevi muitas dezenas de textos contra a Síria. Nunca um país errou tanto, durante tanto tempo e de forma tão continuada. Refiro-me aos EUA.

Procurem nos arquivos deste blog. Desde o primeiro momento das ditas ações rebeldes, o que se tinha na Síria eram ataques terroristas. (V2)

(11) Algumas medidas podem ser tomadas. Senão podemos pôr fim à guerra, podemos dar visibilidade a ela com mais frequência. Devemos rejeitar a ideia de que o sofrimento do povo sírio é normal. Podemos também ajudar aos médicos e enfermeiros a continuarem seus trabalhos. Há diversas entidades que trabalham nas áreas de conflito enviando medicamentos e suprimentos necessários para os hospitais (veja como ajudar no fim do artigo). (C2)

Em (09), o enunciador manifesta-se no discurso, indica seu posicionamento. Em (10), além de haver um "eu" explícito, que também se posiciona no discurso, há um "tu" ao qual se dirige e dá ordens: "procurem nos arquivos deste blog". Já, em (11), há a presença de "nós". Buscando sensibilizar os leitores para a situação síria, o enunciador colocase como pertencente ao grupo, como vemos nos verbos conjugados na primeira pessoa do plural "devemos", "podemos" etc.

(12) Vitória para maniqueístas e oportunistas como Vladimir Putin. Nosso homem em Moscou hoje cobra do mundo o posicionamento entre Assad e o terror; derrota para Barack Obama. O homem das nuances amarga um fiasco estratégico e humanitário na Síria. (V1)

Vladimir Putin é retomado no discurso pela expressão "nosso homem em Moscou". Avaliando este pronome possessivo, "nosso", observa-se a inclusão do enunciador e do interlocutor (ambos, possivelmente, brasileiros), contudo a referência é feita ao presidente russo, Putin. Assim, cumpre refletir o motivo desse pronome possessivo em um contexto em que, teoricamente, não caberia.

Morais (2017), avaliando o uso do pronome "nosso" em um relato esportivo que retratava a rivalidade Brasil e Argentina, indica que seu uso representava uma situação coletiva na qual o enunciador se inseria e acrescentava também seus leitores, apresentando um sofrimento e decepção da derrota brasileira contra a Alemanha, que acabou levando à final Alemanha e Argentina em "nossas terras". A autora ainda aponta que a presença desse pronome também repercutia nos usos de "nós" brasileiros - versus "eles" - argentinos - gerando uma rivalidade que já é conhecida dos dois países, concernente ao futebol. 
Examinando nosso exemplo, entretanto, não é perceptível a aplicação da mesma análise. No texto, não há uma união brasileira a favor de Putin, nem mesmo uma tensão presente entre "nós" x "eles". Nesta retomada, podemos observar um desempenho que rompe com a barreira semântica do pronome possessivo tradicional, devemos compreendê-lo como um uso irônico. Putin não apoia Assad por acreditar que o presidente sírio seja o melhor para manter a tranquilidade no país, seu apoio tem como objetivos tanto manter seu monopólio como principal produtora e exportadora de gás e petróleo quanto continuar com influências no porto de Tartus, presente na Síria que, com a queda de Assad, seria dominado pelos grupos rebeldes, levando-o a perdê-lo, obviamente. Logo, o auxílio de Vladimir Putin na Síria tem objetivos claros e tais já são de conhecimentos de todos. Por já os conhecermos, já fazerem parte de nossa memória, é que se licencia a expressão "nosso", usada aqui, como salientamos, bem além dos conhecimentos semânticos que esse pronome pode trazer, reinterpretando-o em um sentido jocoso.

Novamente, ratificamos, com base nos exemplos de dêixis temporal e pessoal, que os usos linguísticos devem ser avaliados na construção textual, visto que os valores dos elementos da língua vão se formando nas inter-relações que se estabelecem discursivamente. Como já apontou Cortez (2009), as expressões não se restringem aos seus sentidos dicionarizados, mas atualizam-se no contexto discursivo em que estão inseridas.

\section{Conclusões}

Com base no analisado, observamos, assim como já indicaram pesquisas anteriores (MAALEJ, 2003; CABRAL E SANTOS, 2016; MORAIS, 2017), que os processos dêiticos podem ser, de fato, importantes elementos constitutivos na construção da argumentatividade. Em nosso caso, sendo o artigo de opinião, gênero instaurado na tipologia argumentativa, tais objetivos ficam ainda mais salientes, uma vez que o foco do enunciador é convencer seu público alvo de determinada tese.

No que tange à dêixis temporal, foi perceptível uma elasticidade desse conceito. Assim, argumentativamente, o dêitico temporal pode tanto indicar uma inexatidão, eximindo o enunciador de prestar esclarecimentos posteriores, quanto também pode romper sua barreira semântica de alguma data fechada, como vimos com "hoje". 
v. 9 (1)

270-286

Em relação à dêixis pessoal, por sua vez, como é licenciado pelo gênero textual analisado, vimos um enunciador que se inclui no texto, além de também dar ordem aos seus leitores. Entretanto, um processo bem peculiar foi a construção "nosso homem em Moscou", presente em V1, ao tratar de Vladimir Putin.

Como percebemos, a forma pronominal rompe com o uso canônico de pronome possessivo, passando a indicar, em conjunto com toda a estrutura, uma referência irônica ao presidente sírio, apontando que todos já sabem de seu interesse em proteger a Síria, sendo de conhecimento de todos, por isso "nosso". Essa estrutura salienta o caráter criativo da construção textual, em que as palavras ganham diferentes potencialidades discursivas, conforme indica Fairclough (2001).

A criação de novas possibilidades discursivas fez com que o mesmo pronome - nosso - pudesse, a depender do contexto, obter novos sentidos, como ilustrado de uma forma em Morais (2017) e de outra em nosso artigo. Tal aspecto reforça a teoria da argumentação na língua proposta por Anscombre e Ducrot (1988), na qual os enunciados são sempre guiados a determinadas conclusões, contudo tal ocorre a partir de elementos que a língua nos oferece como recursos, dentre esses, a referenciação (KOCH e MARCUSCHI, 1998; KOCH, 2014 [2008]; CAVALCANTE, 2012).

Por fim, ao longo do texto, notamos que a referenciação é um importante elemento na construção de tessitura textual que, a partir das intencionalidades do produtor, auxiliam na elaboração da argumentação, indiciando o leitor a obter determinadas interpretações

Como já apontado anteriormente, mesmo diante de um corpus restrito e com poucos casos de dêixis, almejamos ter ratificado, por meio desse breve artigo, a importância de estudos mais atentos às áreas que mesclem os processos dêiticos à argumentação, visto sua relevância para a construção da tessitura textual.

\section{Referências}

ANSCOMBRE, J. C. e DUCROT, O. L'argumentation dans la langue. Liège/ Bruxelas: Pierre Mardaga, 1988.

APOTHÉLOZ, D. Papel e funcionamento da anáfora na dinâmica textual. In: CAVALCANTE, M. M. et al. (Orgs.). Referenciação. São Paulo: Contexto, 2003. p. 53-84.

BARBOSA, R. S. P. A fuga da contradição e a estratégia do vago: análise de 
trechos de uma entrevista política. EID\&A - Revista Eletrônica de Estudos Integrados em Discurso e Argumentação, Ilhéus, n. 7, p. 215-233, dez. 2014. Disponível em: <http://periodicos.uesc.br/index.php/eidea/article/ view/497/481>. Acesso em: 25 out. 2017.

BENVENISTE, E. Problemas de Linguística Geral I. São Paulo: Editora Nacional, 1976.

CABRAL, A. L T; SANTOS, L W. Dêixis pessoal e verbos na construção de um objeto de discurso argumentativamente orientado. Revista Conexão Letras, V. 11, n. 15, 2016, p.25-37.

CABRAL, A. L. T. Linguística textual e teoria da argumentação na língua: texto e língua em diálogo. In: CAPISTRANO JUNIOR, R.; LINS, M.; ELIAS, V. (Orgs.). Linguística textual: diálogos interdisciplinares. São Paulo: Labrador, 2017. p. 239-262.

CASTIlHO, A. T. de. Nova Gramática do Português Brasileiro. São Paulo: Contexto, 2010

CAVALCANTE, M. M. et al. Dimensões textuais nas perspectivas sociocognitiva e interacional. In: BENTES, A. C.; LEITE, M. Q. (Orgs.). Linguística de texto e análise da conversação: panorama das pesquisas no Brasil. São Paulo: Cortez, 2010. p. 225-261

CAVAlCANTE, M. M. Os sentidos do texto. São Paulo: Contexto, 2012.

et al. Coerência e coesão. In: MARQUESI, S. C; PAULIKONIS, A. L;

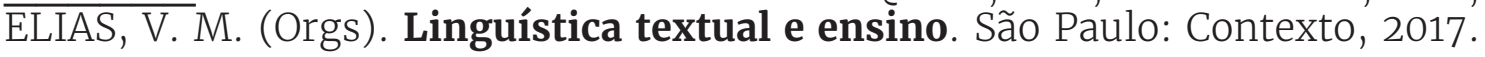
p. 91-107.

CIULLA E SILVA, A. Os processos de referência e suas funções discursivas: 0 universo literário dos contos. 2008. 205f. Tese (Doutorado em Linguística) Centro de Humanidades, Universidade Federal do Ceará, Fortaleza, 2008.

CORTEZ, S. L. Référenciation et construction du point de vue: l'établissement de la visée argumentative du texte. Lenguaje, Colombia, v.37, n.1, p. 95-109, Oct. 2009. Disponível em: <http://revistaingenieria.univalle.edu.co/index. php/lenguaje/article/download/4889/7027/0>. Acesso em 18 jul. 2017.

DUCROT, Oswald. 0 dizer e o dito. Campinas: Pontes, 1987.

FAIRCLOUGH, N. Discurso e mudança social. Brasília: Editora UNB, 2001.

FILLMORE, C. J. Lectures on deixis. Califórnia: CSLI Publications Stanford, 1997 [1984].

FIORIN, J. L. As astúcias da enunciação. 2. ed. São Paulo: Ática, 2001.

FIORIN. Argumentação. São Paulo: Contexto, 2016.

FONSECA, F. I. Dêixis, Tempo e Narração. Porto: Fund. Eng. A. de Almeida, 1992

KOCH, I. V; MARCUSHI, L. A. Processos de Referenciação na produção discursiva. 
V. 9 (1)

270-286

jan-abr 2019

Revista Delta [online]. São Paulo, v. 14, s/p. 1998. Disponível em: <http://www. scielo.br/scielo.php?pid=S0102-44501998000300012escript $=$ sci_arttext $>$. Acesso em 01 dez. 2015.

KOCH, I. V. Desvendando os segredos do texto. 2. ed. São Paulo: Cortez, 2003.

KOCH, I. V. As tramas do texto. 2. ed. São Paulo: Contexto, 2014 [2008, Editora: Lucerna]

MAALEJ, Z. A. Framing and manipulation of person deixis in Hosni Mubarak's last three speeches: a cognitive-pragmatic approach. Pragmatics, v.23, n. 4, p. $633-659,2003$.

MACHADO, G. S. A referenciação em Clarice Lispector: uma comparação entre contos adultos e infantis. 2016. 111 f. Dissertação (Mestrado em Língua Portuguesa) - Instituto de Letras, Universidade do Estado do Rio de Janeiro, Rio de Janeiro, 2016.

MATEU, V. J. A. Deíxis y conocimiento. Anales de filología hispánica, v. 5, p. 145-154, 1990. Disponível em: <http://revistas.um.es/analesfh/article/ view/57701/55591>. Acesso em: 15 fev. 2017.

MONDADA, L.; DUBOIS, D. Construção dos objetos de discurso e categorização: uma abordagem dos processos de referenciação. In: CAVALCANTE, M. M. et al. (Orgs.). Referenciação. São Paulo: Contexto, 2003. p.17-52

MORAIS. M. A. Referenciação em campo: a construção de sentidos na notícia esportiva. 2017. 181 f. Tese (Doutorado em Letras Vernáculas) - Faculdade de Letras, Universidade Federal do Rio de Janeiro, Rio de Janeiro, 2017.

PERDICOYANNI-PALÉOLOGOU, H. Le concept d'anaphore, de cataphore et de déixis en linguistique française. Revue québécoise de linguistique. Montréal, v. 29, n. 2, p. 55-77, 2001. Disponível em: <https://www.erudit.org/en/journals/ rql/2001-v29-n2-rql3575/039441ar.pdf>. Acesso em 18 abr. 2017.

PIRES, V. L.; WERNER, K. C. A dêixis na teoria da enunciação de Benveniste. Revista Letras, Santa Maria, n. 33, p. 145-160, Jul./Dez. 2006. Disponível em: <https://periodicos.ufsm.br/letras/article/view/11926/7347>. Acesso em: 21 nov. 2017.

SANTOS, L. W.; CAVALCANTE, M. M. Referenciação: continuum anáfora-dêixis. Revista Intersecções, São Paulo, v. 12, n. 1, p. 224-246, Mai. 2014. Disponível em: <http://www.portal.anchieta.br/revistas-e livros/interseccoes/pdf/ interseccoes_ano_7_numero_1.pdf>. Acesso em 03 mar. 2017.

SANTOS, L. W.; MORAIS, M. A. Dêixis pessoal e temporal: aspectos sociointeracionais e sociodiscursivos. Revista Investigações, v. 30, n. 2, p. 38-64, 2017. Disponível em <https://periodicos.ufpe.br/revistas/INV/issue/ view/2317/showToc>. Acesso em: 08 jan. 2018. 